\title{
Chapter
}

\section{APOFERRITIN: PROTEIN NANOCARRIER FOR TARGETED DELIVERY}

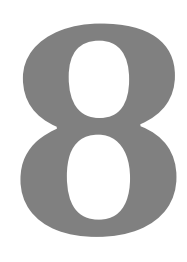

Simona Dostalova1,2, Zbynek Heger ${ }^{1,2}$, Jiri Kudr1,2, Marketa Vaculovicova1,2, Vojtech Adam ${ }^{1,2}$, Marie Stiborova ${ }^{3}$, Tomas Eckschlager ${ }^{4}$, and Rene Kizek ${ }^{1,2^{*}}$

${ }^{1}$ Department of Chemistry and Biochemistry, Laboratory of Metallomics and Nanotechnology, Mendel University in Brno, Zemedelska 1, CZ-613 00 Brno, Czech Republic, European Union ${ }^{2}$ Central European Institute of Technology, Brno University of Technology, Technicka 3058/10, CZ-616 00 Brno, Czech Republic, European Union

3 Department of Biochemistry, Faculty of Science, Charles University, Albertov 2030, Prague 2 CZ-128 40, Czech Republic, European Union ${ }^{4}$ Department of Paediatric Haematology and Oncology, $2^{\text {nd }}$ Faculty of Medicine and University Hospital Motol, Charles University, V Uvalu 84, Prague 5 CZ-150 06, Czech Republic, European Union 


\section{Contents}

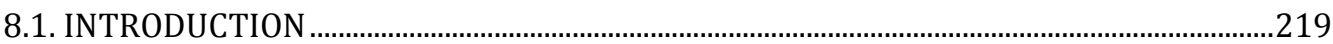

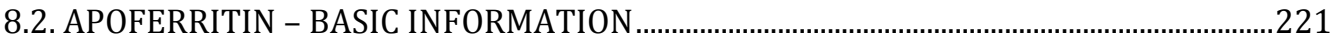

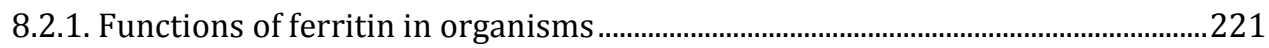

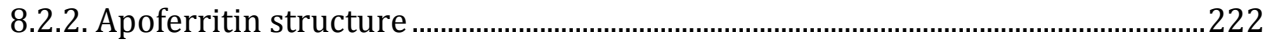

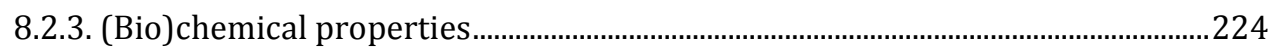

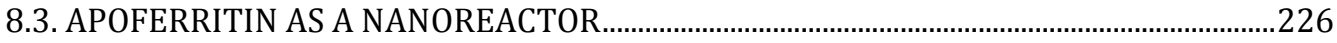

8.3.1. Synthesis of nanoparticles within the apoferritin cage .........................................22

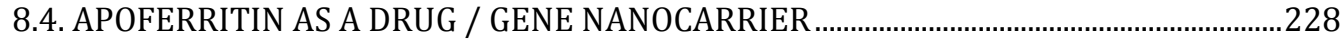

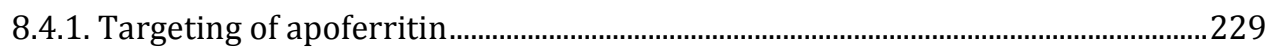

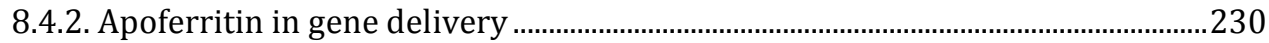

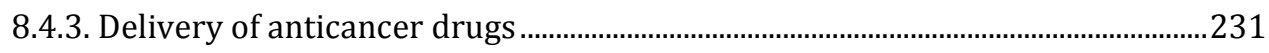

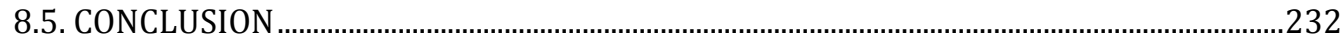

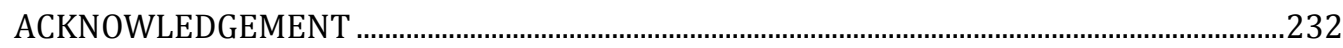

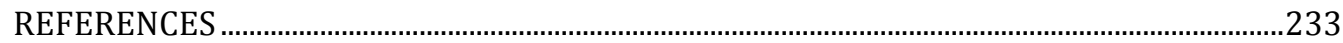




\subsection{INTRODUCTION}

The delivery of drugs using nanoparticles is an important and relatively new branch of nanotechnology. In the past, the development of a new drug concentrated mainly on its effectiveness with low or even no regard to the negative side effects that the drug can have a negative impact on the patient's body. Nowadays, considerable attention is paid towards the elimination of these negative side effects as much as possible [1].

Nano-based drug delivery carriers, or nanocarriers, can consist of wide variety of materials, both organic (polymeric, lipid, protein, or viral) and inorganic [2]. The largest nanocarriers are liposomes, which are 80-200 $\mathrm{nm}$ in diameter [3], polymeric nanoparticles $(40-100 \mathrm{~nm})$ [4] or micelles $(20-60 \mathrm{~nm})[5]$ and the smallest ones are dendrimers with less than $10 \mathrm{~nm}$ in diameter [6]. The use of suitable nanocarriers can significantly reduce negative side effects, as well as increase the biocompatibility, specificity, shelf-life and water solubility of the drug [7]. A diagnostic marker can also be encapsulated within the nanocarrrier for theranostic approach - combining diagnostics and therapy [8].

The hunt for the perfect nanocarrier is still on. The most important property of a perfect nanocarrier is its size. The nanocarrier needs to be small enough to make use of the unique characteristics of tumour tissue and be able to enter cells, but large enough that it is not removed from the body by renal clearance [9]. It also needs to be easily produced, encapsulate large quantities of drug and have reliable mechanism of drug release to prevent premature release of the drug but ensure its release in target cells [10]. The size of the nanocarrier should be uniform and enable surface modification with targeting molecules [11].

Inorganic nanocarriers are easier to produce; however, they are often immunogenic or even toxic to human cells. Natural nanocarriers that can be found in the human body are therefore more suitable [12]. One of these natural nanocarriers is the protein ferritin, responsible for the storage and transfer of iron in most organisms [13]. When the iron is removed, it creates a hollow cage called apoferritin [14].

Apoferritin has been known since 1942, but the increased study came about it in the last 15 years (Figure 1A). It is mostly studied in relation to the nanoparticle formation in its cavity; however, in recent years, it has also been studied as a possible drug delivery vehicle. Figure $1 \mathrm{~B}$ shows the results from the Web of Science database with the keyword "apoferritin" in relation to research areas.

The first mention of apoferritin as a cage for anticancer drug encapsulation was published by Sismek and Kilic in 2005 [15]. The encapsulation of drugs in apoferritin does not require any modification of either drug or carrier 
molecules because it exploits apoferritin behaviour in the surrounding environment [16]. Entry into cells is possible through specific receptors, which are found on most cells in the body. This natural ability of cells to incorporate ferritin can be more enhanced by targeting moieties [17].

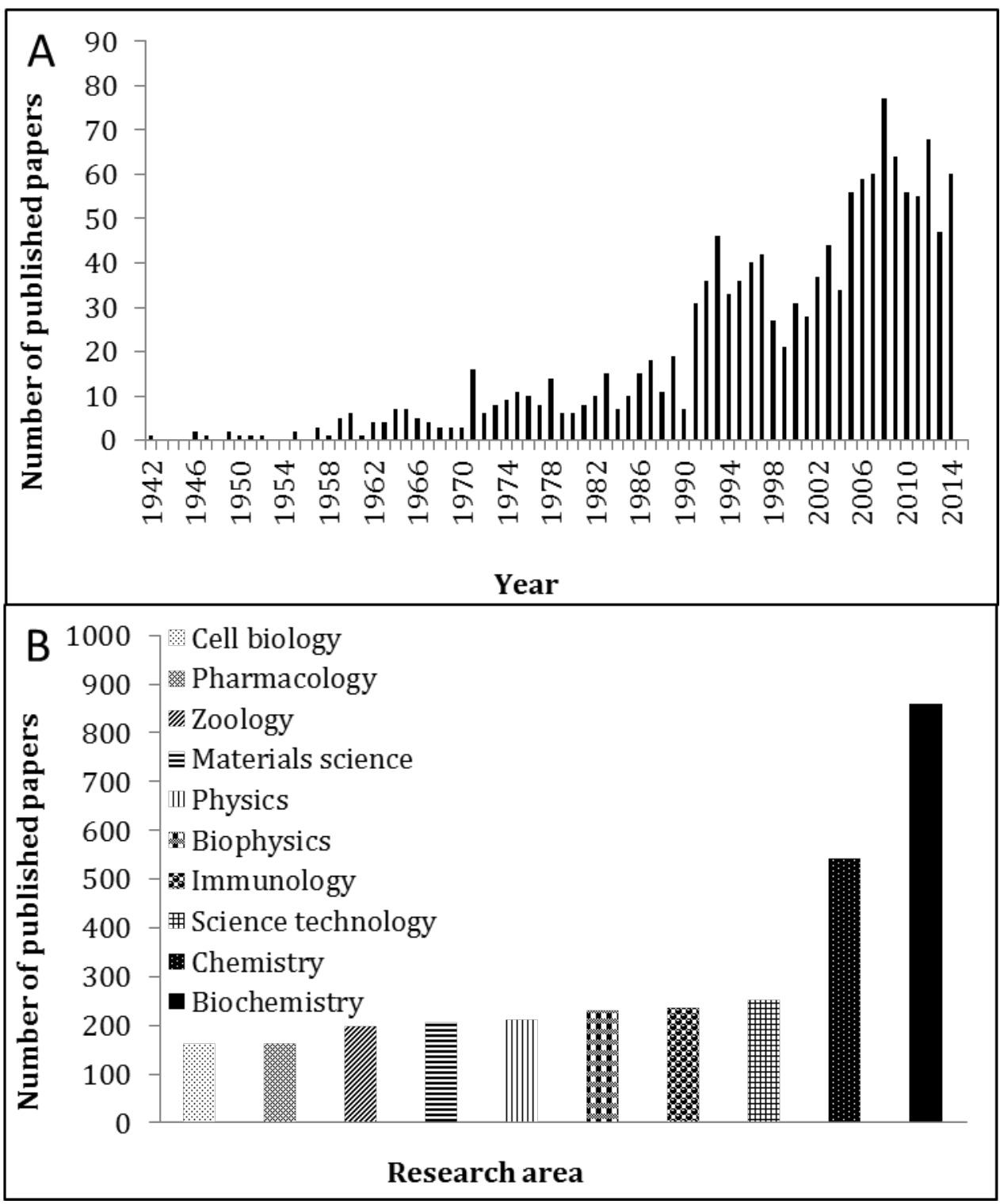

Figure 1. The results from the Web of Science database using the keyword "apoferritin". (1A) Number of published papers per year since 1942. (1B) Number of published papers in different research areas. 


\subsection{APOFERRITIN - BASIC INFORMATION}

Apoferritin is a protein cage, which forms the basis for ferritin [18]. Ferritin is responsible for the storage and transfer of ferric ions, that can be toxic to the organism in higher doses [19]. The apoferritin protein shell is in the form of a hollow rhombic dodecahedron, created by 24 roughly cylindrical subunits of two types [20]. Its most important property is its responsiveness to the surrounding proton concentration, which allows for a very simple encapsulation protocol [21]. The different channels in its shell allow for the entry of small molecules [22].

\subsubsection{Functions of ferritin in organisms}

Iron, in the form of ferrous or ferric ions, is fundamental for the life functions of all eukaryotes and most prokaryotes; however, it is toxic when in excess of that required for cellular homeostasis [23]. Water-soluble ferrous ions $\left(\mathrm{Fe}^{2+}\right)$ can react with metabolically generated hydroxyl radicals and create dangerous reactive oxygen species (ROS) [24]. Many organisms, from humans to microorganisms, possess defensive mechanisms that transform ferrous ions into the insoluble ferric form $\left(\mathrm{Fe}^{3+}\right)$. One of these detoxifying factors is ferritin - major iron-binding protein in non-erythroid cells $[13,25]$.

The phenomenon of ferritin reversible iron storage is supported by the mechanisms involved in the control of their expression, mostly connected to iron and stress, both at the transcriptional and the translational levels (Figure 2) [26,27]. The ferritin-H gene (FTH) is regulated by iron regulatory proteins (IRPs) and contains one iron responsive element (IRE) recognised under a low cellular Fe content by IRP1/2 repressing FTH translation [28]. As a response to high cellular $\mathrm{Fe}$ content, IRP1/2 is degraded via the $26 \mathrm{~S}$ proteasome pathway, which promotes FTH and ferritin-L gene (FTL) translation $[29,30]$. The regulated expression of FTH appears to be of particular importance for cellular adaptation to $\mathrm{Fe}$ overload [26,31]. Transcriptional mechanisms are strictly involved in determining the tissuespecific $\mathrm{H}$ to $\mathrm{L}$ ratio [32]. In the case of oxidative stress, a significant elevation in the expression of ferritin-coding mRNA can be achieved [33]. In many respects, ferritin- $\mathrm{H}$ can also be viewed as a factor responding to inflammation. Inflammatory cytokines, particularly $\mathrm{TNF} \alpha$ and IL-2, up-regulate ferritin biosynthesis [34]. The ferritin shell is able to store 4500 iron atoms in its structure in the form of ferric oxide phosphate, which is structurally similar to ferrihydrite [21], although it generally contains less than 2000 iron atoms in the inner core [35]. The iron stored in the ferritin cavity is usually in the form of ferric hydroxyphosphate micelles [18] and it is readily available to cellular demand [36]. The major pathway of iron release in cells is via the degradation of the ferritin cage [37]. In this degradation, lysosomes play the pivotal role [38]. Thus, lysosomal inhibitors can block ferritin degradation, with simultaneous accumulation of protein cages with iron in organelles. The intra- 
lysosomal degradation of ferritin shields the other cellular components from the potential toxicity of iron, allowing the controlled release of the metal into the cytosol, where it increases the labile iron pool level [19] and induces ferritin expression.

Although ferritin is considered to represent cytoplasmic iron storage, novel functions for ferritin have recently been discovered, including ability to deliver iron into the brain across the blood brain barrier via clathrin mediated endocytosis, using recently described receptors [transferrin receptor 1 (TfR1), $\mathrm{T}$ cell immunoglobulin and mucin domain-containing protein-2 (TIM2), scavenger receptor class A, member 5 (SCARA5)] [39,40]. Ferritin can also be an important factor in angiogenesis, where the binding of ferritin to the antiangiogenic cleaved form of kininogen abrogates its anti-angiogenic function, thus mediating pro-angiogenic processes [41].

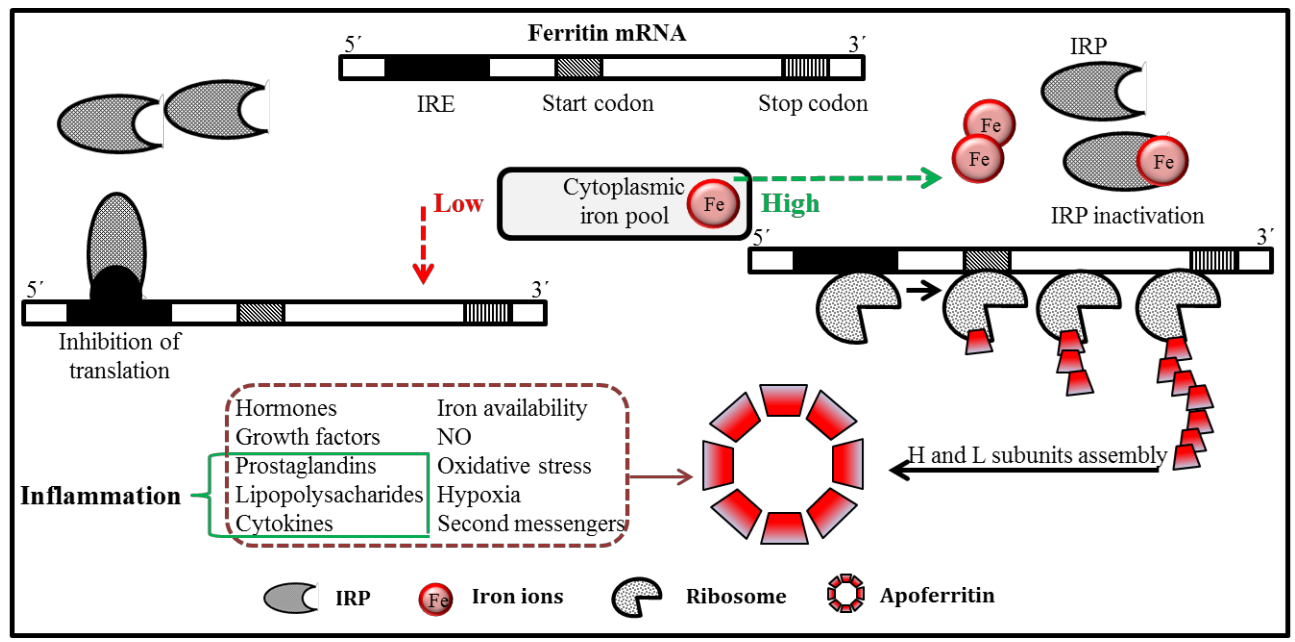

Figure 2. Iron-dependent expression of ferritin on the translational level. IRPs exhibit high affinity towards Fe ions, however with low intracellular amounts of iron, IRPs preferably bind to the iron responsive element (IRE), and thus translation of ferritin is stopped. On the other hand, with high levels of intracellular iron, IRP-Fe complexes are formed and ferritin subunits are translated to form the assembled protein, which can be further used for safe iron storage. Furthermore, possible ways of controlling ferritin expression, which can be involved both at the transcriptional and post-transcriptional levels, are listed.

\subsubsection{Apoferritin structure}

The ferritin protein can be expressed in iron-free conditions, thus creating a hollow nanocage without iron in its structure called apoferritin [42]. Another approach is the reduction of the iron from ferritin with sodium dithionite with subsequent removal by dialysis, which also produces apoferritin [14]. 
The apoferritin cage is $450-475 \mathrm{kDa}$ in size and it forms a shell with an outer diameter of 12-13 nm and an inner diameter of 7-8 $\mathrm{nm}$ [43]. The protein shell is in the shape of a hollow rhombic dodecahedron with 4-3-2 symmetry that forms intersubunit channels along the three- and four-fold axes to accommodate iron [21]. The faces of the dodecahedron are formed by two subunits related by a two-fold symmetry axis at the centre [18]. Each axis is connected to subunits by electrostatic interactions and hydrogen bonding. The two-fold axis is the most stable one, since the greatest number of interaction sites are there. The fewest interaction sites are found in the three-fold axis, the least stable one [44]. The crystal structure of apoferritin contains the ferritin core [42].

The structure of animal apoferritin protein shell is composed of two types of 24 subunits - heavy $(\mathrm{H})$ and light $(\mathrm{L})$ - differing by the molecular weight - 21 and $19 \mathrm{kDa}$, respectively [20], with 53\% sequence identity [45]. The $\mathrm{H}$ and $\mathrm{L}$ sequences are very heterogeneous between (apo)ferritins from different tissues within the same animal species with only $40-50 \%$ homology. However, sequences from the same tissue from different species are very homologous (85-90\%) [20].

The apoferritin subunit is almost cylindrical and it is formed by four $\alpha$-helices with parallel and anti-parallel orientation (H1-H4), showing a left-handed twist [18]. The length of the $\mathrm{H} 1, \mathrm{H} 2$ and $\mathrm{H} 3$ helices is about $4.3 \mathrm{~nm}$ and $\mathrm{H} 4$ is about $5.2 \mathrm{~nm}$ long. The $\alpha$-helices are connected via loops and a short fifth $\alpha$-helix (H5, $1.6 \mathrm{~nm}$ ) is located on the C-terminus, oriented almost at a $60^{\circ}$ angle to the major helices [20]. Almost $75 \%$ of the 174 residues of the subunit are within the $\alpha$-helices, corresponding to residues 14-40, 49-76, 96-123, 127-161 and 163-173 [18]. The short non-helical regions are located on both the $\mathrm{N}$ - and C-termini with two right-handed turns between the $\mathrm{H} 1-\mathrm{H} 2$ and H4-H5 helices [18]. There are abundant side chain interactions within each subunit. Many side chains interact to form hydrophobic cores at the two ends of the helical bundle. A large number of polar and hydrophilic residues, forming a network of hydrogen bonds, are located in the centre of subunit. This part is the most differentiated between the $\mathrm{H}$ and $\mathrm{L}$ subunits. The orientation of the helix bundle and the H5 helix is similar in both subunits, although they differ in the H4-H5 turn - in H subunits, it is formed by three overlapping turns, but in $\mathrm{L}$ subunits it is rather tight with only one amino acid residue between the end of $\mathrm{H} 4$ and the start of $\mathrm{H} 5$ [18]. The length of the apoferritin subunit is $5 \mathrm{~nm}$ with a width of $2.5 \mathrm{~nm}$ [18].

The tissue specificity of subunits is mediated by the different functions of each subunit. The mammalian $\mathrm{H}$ subunit contains a ferroxidase centre in the major helix bundles with a bridging ligand (numbered as E62) between two iron atoms. The L subunit, however, contains a lysine at E59 instead of this residue, blocking the ferroxidase site by forming a salt bridge with glutamic acid at E104 of the same subunit. In addition, strong hydrogen bonding is present among the inter- and intra- L subunits [46]. The $\mathrm{H}$ subunits are thus mainly 
responsible for iron oxidation from $\mathrm{Fe}^{2+}$ to $\mathrm{Fe}^{3+}$ and the $\mathrm{L}$ subunits are responsible for nucleation and mineralisation of iron [47] - only the $\mathrm{H}$ subunit is catalytically active [48], which is in contrast to prokaryotic apoferritin, where each of the subunits possess catalytic activity [49] and is more similar to the animal $\mathrm{H}$ subunit [18]. Due to the structural change, L-subunit-rich apoferritin is much more stable than H-subunit-rich apoferritin [20]. Some apoferritins also contain additional catalytically active subunits called $\mathrm{M}$ [48]. Plant apoferritin subunits are considered to be $\mathrm{H} / \mathrm{L}$ hybrids, since they contain both a ferroxidase centre and a nucleation centre [50].

Apoferritin possesses channels situated at subunit intersections, which connect the apoferritin cavity with the outside environment. Six channels at the four-fold axis are lined with hydrophobic leucine residues [51], representing an energy barrier for ion uptake [52]. These channels are $1.2 \mathrm{~nm}$ long and 0.3-0.4 $\mathrm{nm}$ wide [44] and they are formed by contact between the H5 helices of four subunits from this axis, oriented from the outer to the inner part of the protein shell [18]. In contrast, eight three-fold channels are hydrophilic, 0.3-0.4 $\mathrm{nm}$ long and wide [44] and consist of negatively charged glutamic and aspartic acid residues $[53,54]$. They are formed by a symmetrical convergence of three subunits at this axis which are in contact through the N-terminal ends of helices $\mathrm{H} 1$ and $\mathrm{H} 4$ and the C-terminal ends of $\mathrm{H} 2$ and $\mathrm{H} 3$ [55]. They attract $\mathrm{Fe}^{2+}$ ions and are the location of iron entry [56].

There are extended contacts between pairs of subunits with antiparallel orientation along the two-fold axes (the most stable one), involving helices $\mathrm{H} 1$ and $\mathrm{H} 2$ on each monomer. The loops of these paired subunits are oriented parallel to the two-fold axes [55]. These interactions are essential for the formation of the apoferritin 24-mer [57].

The most characterised apoferritin is from the horse spleen and has been studied since 1937 [20]. Horse spleen apoferritin has an outer diameter of $12 \mathrm{~nm}$ and an inner diameter of $8 \mathrm{~nm}$ [58]. The thickness of the horse spleen apoferritin shell is $2.3 \mathrm{~nm}$ and the volume of its hollow core is $233.2 \mathrm{~nm}^{3}$ with a ferrihydrite core volume of $142.0 \mathrm{~nm}^{3}$ [21]. The ratio between the heavy and light subunits in horse spleen apoferritin is $85-90 \%$ for light subunits and $10-15 \%$ for heavy subunits, which ensures its high stability [20].

\subsection{3. (Bio)chemical properties}

The quarternary structure of the apoferritin cage ensures its high solubility and thermostability [55]. It can withstand a wide range of $\mathrm{pH}(3.4-10.0)$ and still retain its hollow spherical structure of $12.3 \mathrm{~nm}$ in diameter. The denaturation of apoferritin occurs at pH levels below 1.0 or above 13.0. Between pH 1.0 and 3.4, apoferritin undergoes some structural changes. It can also sustain high temperature; denaturation occurs when horse spleen apoferritin is heated above $80^{\circ} \mathrm{C}$ for $10 \mathrm{~min}$ [21]. 
At neutral $\mathrm{pH}$, the external surface of apoferritin has a net negative charge. Both the external and internal surface of apoferritin can be modified with different moieties [48] and through genetic and chemical modifications [59]. Some substances can bind to the apoferritin surface through hydrogen bonding (non-ionic molecules) or electrostatic interactions (ionic molecules) [60]. Small molecules (less than $2 \mathrm{~nm}$ ) can enter the apoferritin cavity through channels in its structure via diffusion [22]. Electron transfer through the apoferritin shell is also possible [61]. Furthermore, apoferritin metal derivatives can coprecipitate with specific polycations and can thus be used for protein sensing [62].

The important properties of apoferritin for its use as a nanocarrier for drug delivery are its self-assembling ability and the fact that its structure is dependent on the surrounding environment. It can reversibly dissociate and associate based on the $\mathrm{pH}[21]$.

At pH levels above 3.4, apoferritin has spherical structure. Below pH 3.4, it becomes unstable, collapses and disassembles. The disassembly of apoferritin occurs stepwise through structural intermediates [21]. It starts at the weakest site, the three-fold axis, in the vicinity of the three-fold channels in the opposite direction [44]. First of all, at $\mathrm{pH}$ in the range of 3.4-2.4, apoferritin has an overall hollow spherical shape with changes in the structural details. At $\mathrm{pH} 3.24$, a pair of subunits is disassembled from each of the north and south poles of apoferritin, creating two holes with a diameter of $6.5 \mathrm{~nm}$. One more subunit is disassembled from each pole at $\mathrm{pH} 3.08$, creating holes $6.7 \times 9.2 \mathrm{~nm}$ in size. Another subunit (a total of eight) is dissociated from each pole at $\mathrm{pH} 2.85$, still retaining the overall spherical structure. At $\mathrm{pH} 2.66$, due to the loss of subunits, apoferritin becomes a headset-shaped structure and below $\mathrm{pH} 2.4$ apoferritin becomes even more opened. Ultimately, at pH 1.96, there are significant changes to apoferritin, which starts to form a rodlike structure consisting of oligomers, mostly trimers [21]. Moreover, below pH 0.8, the disassembled subunits are aggregated, which is attributed to denaturation and driven by van der Waals and non-specific hydrogen bonding. Apoferritin in such a highly acidic environment is inhomogenous, polydisperse, and it has no definite size [21].

The reassembly process of apoferritin is dependent on the disassembly process. It can never recover to the intact spherical shape. Furthermore, if disassembly was conducted at $\mathrm{pH} 1.96$ or below (to a rodlike structure), the structural recovery is limited to the headset-shape structure formed by 12 subunits. If the disassembly was limited to the headset-shape structure (between $\mathrm{pH} 3.4$ and 2.0), the resulting apoferritin has an overall spherical structure with two hole defects $6.5 \mathrm{~nm}$ in size at the north and south poles, and is formed by 20 subunits. The difference in reassembly recovery is probably due to the improper contact angles between the dimer and monomer components of the rodlike structure, thus the resulting headset structure 
cannot adopt more trimers or monomers to complete the reassembly process [21].

The reassembled spherical structure with two hole defects can be useful for nanoparticle fabrication since the holes can serve as channels for mass transport [21].

\subsection{APOFERRITIN AS A NANOREACTOR}

Apoferritin's cage is most often used as a template in nanoparticle or quantum dot (QD) synthesis [63]. It can also be used as a scaffold for supramolecular wrapping, nanoscale incarceration and nanostructure templating [64]. The entry of ions for nanoparticle formation is possible through the many channels in the shell of apoferritin [22]. Apoferritin used as a nanoreactor was found to be an effective tool for the synthesis of various well-defined nanoparticles.

\subsubsection{Synthesis of nanoparticles within the apoferritin cage}

Ferritins are known as iron storage proteins and similar biomimetic strategies as in case of iron can be used to synthesise other inorganic nanoparticles (NPs) (oxide, metallic and semiconductor) within the apoferritin cavity. It is able to accommodate several inorganic molecules and metal ions. Positively charged ions can enter the apoferritin cavity in the same way as iron. However, it has not yet been elucidated how anions enter ferritins. Recently, it was shown that highly conserved glutamic acid residues mediate iron transfer from channels to the ferritin enzyme site and with aspartate-promoted nanoparticle formation $[65,66]$.

Oxide nanoparticles and semiconductor nanocrystals (QD's) with biocompatible and bioactive properties can be synthesised inside apoferritin $[67,68]$. Ferritin with iron oxide cores can be sulphidised with $\mathrm{H}_{2} \mathrm{~S} / \mathrm{Na}_{2} \mathrm{~S}$ within the cavity and used to produce FeS NPs. Moreover, redox-active metal ions can be synthesised in apoferritin with the most satisfying results found for Mn(II), which can create amorphous manganese oxide cores [68]. Other bivalent metal ions like $\mathrm{Cd}^{2+}$ bind to the apoferritin cavity and thus can be used for the reconstruction of semiconductor NPs inside apoferritin [67,69]. QDs and nucleated nanoscale CdS crystallites within the apoferritin cavity, created by the reaction of $\mathrm{Cd}^{2+}$ and $\mathrm{HS}^{-}$, can offer unique photoresponsive and photoredox properties. These CdS NPs are preferentially developed within the cavity rather than on the surface and their size can be tuned. The presence of native iron-containing cores reduces CdS NP growth. In this process, the charged lining of the protein channels and cavity are important [67].

In a case of creating semiconductor NPs inside apoferritin, successful synthesis depends on the suppression of chemical reactions outside of the cavity. Firstly, positive metal ions need to be introduced to the demetallated protein cavity 
(apoferritin) and condensed at nucleation sites, which after the addition of anions encourages nucleation. Anion induction in the cavity should also be faster than chemical reactions outside [69].

In the case of II-VI semiconductor nanocrystals, it must be pointed out that they are usually prepared in non-polar organic solvents with phosphine ligands. It means that their aqueous dissolution requires surface modification with more polar or hydrophilic molecules. Bio-templated synthesis of such particles benefits not only from the water solubility of the protein shell but also from its biocompatibility and broadens their application possibilities. These properties can be achieved not only by using the nanoreactor route but also by using apoferritin shell reassembly in the presence of target NPs [63].

The synthesis of ZnO NPs within the apoferritin cavity can be very difficult. Since a concentration of $\mathrm{OH}^{-}$anions around $10 \mathrm{mM}(\sim \mathrm{pH} 11)$ is required for ZnO formation, most apoferritin molecules are denatured during the procedure. However, $\mathrm{ZnO}$ nanoparticles can be synthesised within the apoferritin cavity if $\mathrm{Zn}^{2+}$ is stabilised in water against reaction with $\mathrm{OH}^{-}$by the addition of ammonium water $\left[\mathrm{Zn}\left(\mathrm{NH}_{3}\right)_{4}{ }^{2+}\right]$ [54]. When this complex is situated near the threefold channel, $\mathrm{Zn}^{2+}$ decouples from the complex due to chemical equilibrium and flows inside. Zinc inside the cavity is hydroxylated to $\mathrm{Zn}(\mathrm{OH})_{2}$ due to $\mathrm{OH}^{-}$diffusion inside and subsequently becomes $\mathrm{ZnO}$ by a dehydration reaction. Also, other nanomaterials such as $\mathrm{Zn}_{3}\left(\mathrm{PO}_{4}\right)_{2}, \mathrm{Cd}_{3}\left(\mathrm{PO}_{4}\right)_{2}, \mathrm{~Pb}_{3}\left(\mathrm{PO}_{4}\right)_{2}$, $\mathrm{CO}_{3} \mathrm{O}_{4}, \mathrm{ZnSe}, \mathrm{Pd}, \mathrm{Ni}, \mathrm{Cr}$, and several other nanoparticles can be synthesised using apoferritin [53,65,70-73]. The scheme of NP synthesis using apoferritin is presented in Figure 3.

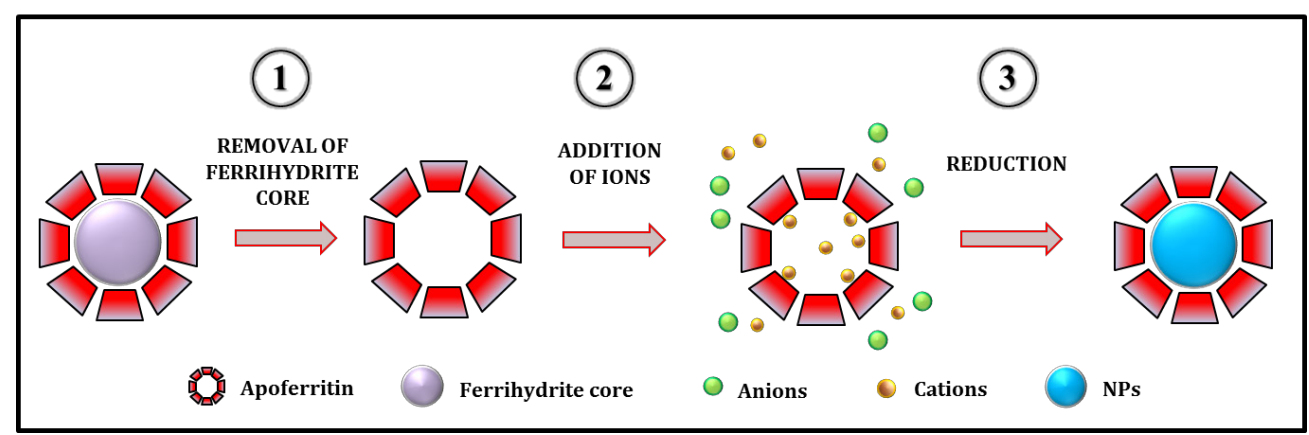

Figure 3. A scheme of the individual steps of NP synthesis within ferritin. The removal of the ferrihydrite core of ferritin (1). The addition of cations and anions to apoferritin (2). Cations condense at nucleation sites and anions remain outside the cavity because of a large energy barrier. NPs are created inside the cavity after reduction (3).

An attractive apoferritin nanoreactor application is the reconstruction of ferromagnetic iron oxide magnetite or maghemite $\left(\mathrm{Fe}_{3} \mathrm{O}_{4} / \mathrm{Fe}_{2} \mathrm{O}_{3}\right)$ within the 
apoferritin cavity. This artificial magnetic protein is called magnetoferritin and it can be used as a dispersed bioorganic and magnetic material in various medical applications [74]. A solution of $\left(\mathrm{NH}_{4}\right)_{2} \mathrm{Fe}\left(\mathrm{SO}_{4}\right)_{2} \cdot 6 \mathrm{H}_{2} \mathrm{O}$ is slowly and in small increments added to a buffered solution of apoferritin (pH 8.5) along with small amounts of air to produce slow oxidation. Subsequently, anaerobic synthesis with the addition of a stoichiometric amount of oxidant probably reduces the creation of non-magnetic ferric oxides [75]. The creation of ferric/ferromagnetic nanoparticles is important in several technological applications like high-density magnetic data storage [76].

\subsection{APOFERRITIN AS A DRUG / GENE NANOCARRIER}

The spherical cage in apoferritin can be used for the encapsulation of fluorescent dyes [77], drugs [78-85], magnetic resonance imaging contrast agents [86,87], genes [88] or other compounds [89]. Due to the self-assembly activity of apoferritin and its response to the surrounding environment, it has several advantages for use as a nanocarrier. The formed cavities have uniform size, ensuring the high reproducibility of cargo encapsulation. In addition, the encapsulation protocol is very simple, based only on $\mathrm{pH}$ changes in the presence of molecules that are to be encapsulated. It shows very low cytotoxicity and high biocompatibility [90].

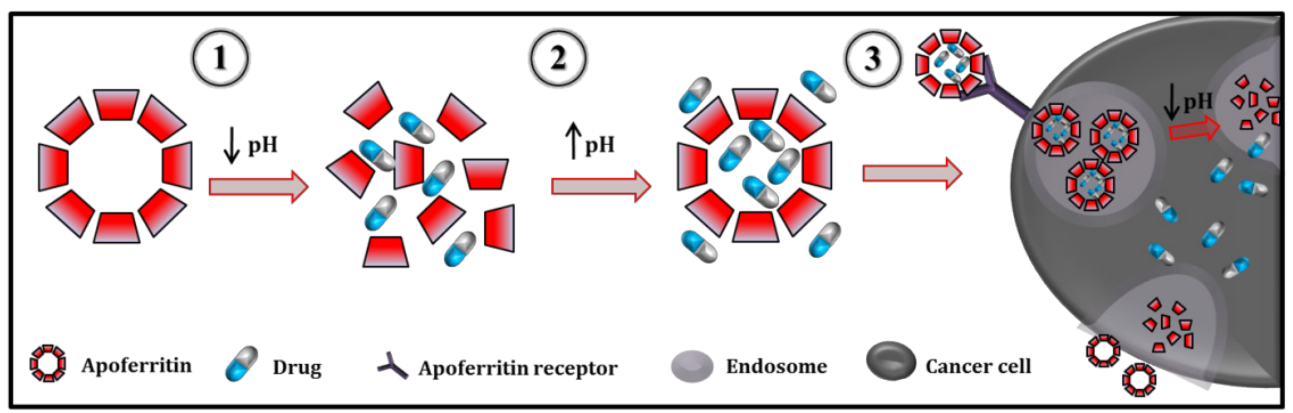

Figure 4. A scheme of the drug encapsulation protocol in apoferritin and its release in cancer cells. The lower $\mathrm{pH}$ disassociates the subunits that are mixed with the drug (1). After increasing the $\mathrm{pH}$, the drug is encapsulated (2). The acidification of the endosome disassociates apoferritin and the drug is released (3).

Apoferritin is mostly discussed in relation to cancer treatment. In patients, when apoferritin is administered intravenously, there is close to no undesired release of cargo due to the near-to-neutral $\mathrm{pH}$. However, the low endosomal $\mathrm{pH}$ in cancer cells allows the release of the cargo [88]. Figure 4 shows the encapsulation protocol and the release of apoferritin cargo in cancer cells. 


\subsubsection{Targeting of apoferritin}

Apoferritin can enter target cancer cells through both passive and active targeting. Passive targeting is enabled by the enhanced permeability and retention (EPR) effect [91]. To ensure the EPR effect, the spherical nanocarriers should be less than $100 \mathrm{~nm}$ in size [92-94]. Healthy blood vessels have pores of $10 \mathrm{~nm}$, so the nanocarrier needs to be larger [10]. Apoferritin with its diameter of $12.3 \mathrm{~nm}$ has just the right size. However, nanoparticles smaller than $20 \mathrm{~nm}$, including apoferritin, can undesirably be removed from the body via renal clearance [9]. It is therefore suitable to increase the size of apoferritin slightly via surface modifications. Moreover, to prolong the blood clearance time of apoferritin, its surface can be modified with dextran [95].

Apoferritin can enter cells through receptor-mediated endocytosis [17] as well as clathrin-mediated endocytosis by its specific receptors, TfR1 [96] and SCARA5 [97]. However, these receptors can be found not only on cancer cell membranes but also on the surface of many healthy cells [98], such as TfR1 in kidney cells. Therefore, it is better to modify the surface of apoferritin with actively targeting moieties, which can also increase its size. This way, the apoferritin gets to the vicinity of the tumour by passive targeting (the EPR effect) and can enter cells by active targeting.

As a target, tumour cells or tumour endothelial cells are employed [99]. Using cancer cells as the target, apoferritin not only accumulates at the tumour site, but its uptake by cancer cells is enhanced. The targeting of cancer endothelial cells can even inhibit the growth of tumour blood vessels, leaving the tumour without an oxygen supply. A suitable targeting moiety should have its receptor homogenously overexpressed on the cancer cell membrane or endothelium [100].

The apoferritin surface can be modified with antibodies [101], antibody fragments [89], proteins [102], peptides [103], vitamins [104], DNA or RNA aptamers [105] or small molecules such as folic acid [106]. Covalent bonding of surface lysine with targeting moieties can be used for the surface modification of apoferritin [107].

The simplest targeting molecule is folic acid or folate. Folate receptors $\alpha$ and $\beta$ are overexpressed by many types of cancer cells due to their greatly enhanced metabolism [108]. However, folic acid is a very small molecule and even with this modification, apoferritin is still small enough to be removed from blood via renal clearance.

Aptamers, i.e. DNA or RNA oligonucleotides, can bind to a variety of targets, including prostate-specific membrane antigen (PSMA) [109] or nucleonin [110]. They can be effectively used with other nanocarriers, but apoferritin modified with these aptamers may still be too small and thus removed from the organism through renal clearance. However, surface modification of 
apoferritin with aptamers and horseradish peroxidase can serve as a biosensor [105]. Its pH responsiveness can also be employed in biosensor design [111].

Among the possible targeting moieties are cyclic or linear derivatives of arginine-glycine-aspartic acid (RGD) peptides. The introduction of this peptide onto the apoferritin surface can be performed by genetic modification [112]. RGD is a short amino acid sequence, which has high affinity to integrin $\alpha_{\mathrm{v}} \beta_{3}$. The $\alpha_{v} \beta_{3}$ integrin is found in tumour angiogenic blood-vessel endothelial cells and cancer cells [103]. Apoferritin modification with these RGD derivatives leads to higher tumour uptake and better growth inhibition when compared to the free drug [113].

The largest apoferritin particles are achieved by modification with antibodies. When using native antibodies, they can be immunogenic by binding of their Fc domain to the Fc receptors on healthy cells. To eliminate this problem, it is possible to use antibody fragments, containing only the Fab region [114] or inactivate the $\mathrm{Fc}$ region by binding to a peptide protein $\mathrm{G}$ derivative which can be attached to the apoferritin surface [115]. Moreover, using this approach ensures the correct orientation of antibodies with the antigen-binding site facing outwards from the nanocarrier.

\subsubsection{Apoferritin in gene delivery}

Recently, considerable attention has been focused on the delivery of genes or siRNAs to target cells for gene therapy. Via this process, it is possible to insert [116], remove [117], modify [118] or silence [119] defective genes, thus treating even genetically inherited disease. The most studied nanocarriers for the gene delivery include viral particles [120], liposomes [121] and polymers [122]. Many artificial nanoparticles, however, can have negative side effects once administered to the patient. These include immunogenicity [123] or even embolisation because of nanocarrier aggregation [124]. Nanocarriers naturally found in the human body are therefore more suitable for these applications [12].

A suitable nanocarrier for gene delivery should be able to protect the genetic cargo from degradation by nucleases. Moreover, it should not allow premature release of the cargo but should be able to release the cargo in target cells, thus delivering it to the nucleus [125].

Since apoferritin can be loaded with a wide spectrum of molecules via the disassembly/reassembly process [79], it is also possible to use apoferritin as a carrier for the delivery of genes. It is also a molecule naturally found in the human body and it possesses many of the abovementioned criteria making it suitable as a gene nanocarrier [18]. Also, its surface can be modified with moieties that are useful for gene delivery, such as poly(ethylenimine) $[126,127]$. 


\subsubsection{Delivery of anticancer drugs}

The delivery of anticancer drugs using apoferritin as a nanocarrier can lower the negative side effects of these drugs, such as the cardiotoxicity of doxorubicin [79] or seizures caused by cisplatin administration [128]. With water-soluble apoferritin, it is possible to dissolve drugs that are normally insoluble in water [7]. Due to the passive and active targeting of apoferritin, the drug concentration in the vicinity of the tumour is increased by $100-400 \%$ [91], but the total administered dose can be significantly lowered [129]. The encapsulation of drugs in apoferritin increases their specificity and biocompatibility [130], as well as their shelf-life [131]. Furthermore, since apoferritin is a major iron storage protein in humans, it has excellent biocompatibility and low immunogenicity [113].

After encapsulation, apoferritin retains its structure and the encapsulation does not influence any groups on the apoferritin surface [85]. In addition, the molecules encapsulated in the apoferritin cavity can retain their properties, such as fluorescence [90], which is very convenient for theranostic uses as a diagnostic marker. The encapsulated drug also retains its therapeutic properties [132]. The very first therapeutic molecule encapsulated in apoferritin was doxorubicin, with 28 doxorubicin molecules encapsulated within one apoferritin molecule [16]. Other cytotoxic drugs, such as daunomycin [133], cisplatin [101], carboplatin [128], and oxaliplatin can easily be encapsulated in apoferritin using the same procedure; these complexes are able to enter tumour cells [85]. When a drug is encapsulated within apoferritin, its toxicity to healthy cells is significantly lowered, while it is still toxic to cancer cells [81]. The maximum tolerated dose of apoferritin with an encapsulated drug is four times higher than for the free drug. Moreover, no additional administration of drug is required [134].

During the acidification of the endosome, the drug is gradually released [135]. The release can also be controlled by external stimuli. For this purpose, the apoferitin surface can be modified with thermoresponsive polymers [136]. Furthermore, it is possible to produce thin apoferritin films with controllable release by assembling negatively charged apoferritin on highly positively charged nanostrands [137].

It is possible to create chimeras by fusing apoferritin with other proteins, such as hemagglutinin. This can create particles with immunisation properties to use as more gentle vaccination agents [138].

The delivery of anticancer drugs can be combined with gene therapy to achieve even higher treatment efficiency [139]. The surface of apoferritin can also be modified with biotin and connected to streptavidin-coated magnetic nano- or microparticles to help guide the movement of apoferritin through the patient's body using an external magnetic field and to combine the targeted drug delivery with hyperthermic therapy [79]. Photosensitisers can be encapsulated 
within apoferritin for the combination of photodynamic therapy and chemotherapy [140].

Due to the stability of apoferritin, there is almost no undesired drug leakage with prolonged storage [16]. Its stability and bioavailability can be further increased by the encapsulation of antioxidant molecules, such as curcumin [132]. The only undesired drug release occurs through the two hole defects left after the reassembly of apoferritin at low $\mathrm{pH}$. When drugs containing metals are used, the association with metal binding sites on the interior of apoferritin eliminates this problem [141]. Non-metal-containing drugs can be precomplexed with a metal such as iron or better yet copper for such internalisation. This procedure can be applied to a wide variety of drugs, including doxorubicin, and the encapsulation efficiency is higher than with the simple disassembly/reassembly protocol [113].

Apoferritin can be used not only as a nanocarrier for anticancer drugs, but also for other drugs, including antimicrobial molecules, such as silver ions and silver nanoparticles that can be used in the treatment of methicillin-resistant Staphylococcus aureus [80].

\subsection{CONCLUSION}

The apoferritin protein nanocage is a very suitable molecule for use as a drug delivery vehicle. Its properties, such as size, excellent biocompatibility, easy modification and simple encapsulation protocol based on structural changes in different $\mathrm{pH}$, present a large advantage when compared to the other nanocarriers. It contains multiple channels in its structure, employable for small nanoparticle synthesis.

Due to the encapsulation procedure, a wide variety of different molecules can be encapsulated within its cavity. It can therefore be used for simple chemotherapy, but also the combination of therapy with diagnostics, chemotherapy and photodynamic therapy, gene therapy or hyperthermia therapy. It can be used in not only the treatment of cancer but also other diseases, including bacterial infections.

The size of apoferritin is suitable for passive targeting to tumours and its surface can be modified with a variety of targeting moieties for specific use. Due to all these advantages, apoferritin might very well be the perfect molecule for nanomedicine.

\section{ACKNOWLEDGEMENT}

Financial support from GA CR NANOCHEMO 14-18344S is gratefully acknowledged. 


\section{REFERENCES}

1. J. Drbohlavova, J. Chomoucka, V. Adam, M. Ryvolova, T. Eckschlager, J. Hubalek, R. Kizek. Curr. Drug Metab. 14 (2013) 547-564.

2. D. Peer, J.M. Karp, S. Hong, O.C. FaroKhzad, R. Margalit, R. Langer. Nat. Nanotechnol. 2 (2007) 751-760.

3. G.C. Vaz, A. Bahia, F.C.D. Muller-Ribeiro, C.H. Xavier, K.P. Patel, R.A.S. Santos, F.A. Moreira, F. Frezard, M.A.P. Fontes. Neuroscience 285 (2015) 60-69.

4. A. Cernat, E. Bodoki, C. Farcau, S. Astilean, S. Griveau, F. Bedioui, R. Sandulescu. J. Nanosci. Nanotechnol. 15 (2015) 3359-3364.

5. H.Q. Zhang, L.L. Zhao, L.J. Chu, X. Han, G.X. Zhai. J. Colloid Interface Sci. 434 (2014) 40-47.

6. H.R. Alanagh, M.E. Khosroshahi, M. Tajabadi, H. Keshvari. J. Supercond. Nov. Magn. 27 (2014) 2337-2345.

7. F. Kratz, A. Warnecke. J. Control. Release 164 (2012) 221-235.

8. B. Leonard. Cancer nanotechnology: going small for big advances: Using nanotechnology to advance cancer diagnosis, prevention and treatment, DIANE Publishing Company, Philadelphia, USA, 2009, p. 22.

9. T.M. Allen, P.R. Cullis. Science 303 (2004) 1818-1822.

10. B. Sumer, J.M. Gao. Nanomedicine 3 (2008) 137-140.

11. S. Svenson. Mol. Pharm. 10 (2013) 848-856.

12. J. Panyam, V. Labhasetwar. Adv. Drug Deliv. Rev. 55 (2003) 329-347.

13. J.L. Smith. Crit. Rev. Microbiol. 30 (2004) 173-185.

14. R. Kopp, A. Vogt, G. Maass. Nature 202 (1964) 1211-1212.

15. E. Simsek, M.A. Kilic. J. Magn. Magn. Mater. 293 (2005) 509-513.

16. M.A. Kilic, E. Ozlu, S. Calis. J. Biomed. Nanotechnol. 8 (2012) 508-514.

17. W. Lu, C.Y. Xiong, R. Zhang, L.F. Shi, M. Huang, G.D. Zhang, S.L. Song, Q. Huang, G.Y. Liu, C. Li. J. Control. Release 161 (2012) 959-966.

18. R.R. Crichton, J.P. Declercq. Biochim. Biophys. Acta, Gen. Subj. 1800 (2010) 706-718.

19. T. Asano, M. Komatsu, Y. Yamaguchi-Iwai, F. Ishikawa, N. Mizushima, K. Iwai. Mol. Cell. Biol. 31 (2011) 2040-2052.

20. B. Gallois, B.L. D'Estaintot, M.A. Michaux, A. Dautant, T. Granier, G. Precigoux, J.A. Soruco, F. Roland, O. ChavasAlba, A. Herbas, R.R. Crichton. J. Biol. Inorg. Chem. 2 (1997) 360-367.

21. M. Kim, Y. Rho, K.S. Jin, B. Ahn, S. Jung, H. Kim, M. Ree. Biomacromolecules 12 (2011) 1629-1640.

22. D.W. Yang, K. Nagayama. Biochem. J. 307 (1995) 253-256.

23. B. Benyamin, T. Esko, J.S. Ried, A. Radhakrishnan, S.H. Vermeulen, M. Traglia, M. Gogele, D. Anderson, L. Broer, C. Podmore, J.A. Luan, Z. Kutalik, S. Sanna, P. van der Meer, T. Tanaka, F.D. Wang, H.J. Westra, L. Franke, E. Mihailov, L. Milani, J. Haldin, J. Winkelmann, T. Meitinger, J. Thiery, A. Peters, M. Waldenberger, A. Rendon, J. Jolley, J. Sambrook, L.A. Kiemeney, F.C. Sweep, C.F. Sala, C. Schwienbacher, I. Pichler, J. Hui, A. Demirkan, A. Isaacs, N. Amin, M. Steri, G. Waeber, N. Verweij, J.E. Powell, D.R. Nyholt, A.C. Heath, P.A.F. Madden, P.M. Visscher, M.J. Wright, G.W. Montgomery, N.G. Martin, D. Hernandez, S. Bandinelli, P. van der Harst, M. Uda, P. Vollenweider, R.A. 
Scott, C. Langenberg, N.J. Wareham, C. van Duijn, J. Beilby, P.P. Pramstaller, A.A. Hicks, W.H. Ouwehand, K. Oexle, C. Gieger, A. Metspalu, C. Camaschella, D. Toniolo, D.W. Swinkels, J.B. Whitfield. Nat. Commun. 5 (2014) 4926.

24. H. Jegasothy, R. Weerakkody, S. Selby-Pham, L.E. Bennett. Biometals 27 (2014) 1371-1382.

25. B.E. Bulvik, E. Berenshtein, E.G. Meyron-Holtz, A.M. Konijn, M. Chevion. PLoS One 7 (2012) e48947.

26. F.M. Torti, S.V. Torti. Blood 99 (2002) 3505-3516.

27. E.C. Theil. Biometals 20 (2007) 513-521.

28. J.B. Harford, R.D. Klausner. Enzyme 44 (1990) 28-41.

29. M.W. Hentze, S.W. Caughman, T.A. Rouault, J.G. Barriocanal, A. Dancis, J.B. Harford, R.D. Klausner. Science 238 (1987) 1570-1573.

30. K. Iwai, S.K. Drake, N.B. Wehr, A.M. Weissman, T. LaVaute, N. Minato, R.D. Klausner, R.L. Levine, T.A. Rouault. Proc. Natl. Acad. Sci. U. S. A. 95 (1998) 4924-4928.

31. J.T. Rogers, J.L. Andriotakis, L. Lacroix, G.P. Durmowicz, K.D. Kasschau, K.R. Bridges. Nucleic Acids Res. 22 (1994) 2678-2686.

32. G. Cairo, L. Bardella, L. Schiaffonati, P. Arosio, S. Levi, A. Bernellizazzera, Biochem. Biophys. Res. Commun. 133 (1985) 314-321.

33. K.J. Hintze, E.C. Theil. Proc. Natl. Acad. Sci. U. S. A. 102 (2005) 15048-15052.

34. L.L. Miller, S.C. Miller, S.V. Torti, Y. Tsuji, F.M. Torti. Proc. Natl. Acad. Sci. U. S. A. 88 (1991) 4946-4950.

35. J. Swift, C.A. Butts, J. Cheung-Lau, V. Yerubandi, I.J. Dmochowski. Langmuir 25 (2009) 5219-5225.

36. D. Finazzi, P. Arosio. Arch. Toxicol. 88 (2014) 1787-1802.

37. J. Truty, R. Malpe, M.C. Linder. J. Biol. Chem. 276 (2001) 48775-48780.

38. T.Z. Kidane, E. Sauble, M.C. Linder. Am. J. Physiol.-Cell Physiol. 291 (2006) C445-C455.

39. V. Licker, N. Turck, E. Kovari, K. Burkhardt, M. Cote, M. Surini-Demiri, J.A. Lobrinus, J.C. Sanchez, P.R. Burkhard. Proteomics 14 (2014) 784-794.

40. E.G. Meyron-Holtz, S. Moshe-Belizowski, L.A. Cohen. J. Neural Transm. 118 (2011) 337-347.

41. L.G. Coffman, D. Parsonage, R. D'Agostino, F.M. Torti, S.V. Torti. Proc. Natl. Acad. Sci. U. S. A. 106 (2009) 570-575.

42. L.S. Vedula, G. Brannigan, N.J. Economou, J. Xi, M.A. Hall, R. Liu, M.J. Rossi, W.P. Dailey, K.C. Grasty, M.L. Klein, R.G. Eckenhoff, P.J. Loll. J. Biol. Chem. 284 (2009) 24176-24184.

43. W. Haussler. Chem. Phys. 292 (2003) 425-434.

44. T. Granier, B. Gallois, A. Dautant, B.L. Destaintot, G. Precigoux. Acta Crystallogr. Sect. D, Biol. Crystallogr. 53 (1997) 580-587.

45. H. Fukano, T. Takahashi, M. Aizawa, H. Yoshimura. Inorg. Chem. 50 (2011) 6526-6532.

46. K. Yoshizawa, Y. Mishima, S.Y. Park, J.G. Heddle, J.R.H. Tame, K. Iwahori, M. Kobayashi, L. Yamashita. J. Biochem. 142 (2007) 707-713.

47. S. Levi, S.J. Yewdall, P.M. Harrison, P. Santambrogio, A. Cozzi, E. Rovida, A. Albertini, P. Arosio. Biochem. J. 288 (1992) 591-596.

48. E.C. Theil, R.K. Behera, T. Tosha. Coord. Chem. Rev. 257 (2013) 579-586.

49. E.C. Theil. Annu. Rev. Biochem. 56 (1987) 289-315. 
50. J.F. Briat, C. Duc, K. Ravet, F. Gaymard. Biochim. Biophys. Acta, Gen. Subj. 1800 (2010) 806-814.

51. G.C. Ford, P.M. Harrison, D.W. Rice, J.M.A. Smith, A. Treffry, J.L. White, J. Yariv. Philos. Trans. R. Soc. Lond. Ser. B, Biol. Sci. 304 (1984) 551-565.

52. T. Takahashi, S. Kuyucak. Biophys. J. 84 (2003) 2256-2263.

53. K. Iwahori, K. Yoshizawa, M. Muraoka, I. Yamashita. Inorg. Chem. 44 (2005) 6393-6400.

54. Y. Suzumoto, M. Okuda, I. Yamashita. Cryst. Growth Des. 12 (2012) 4130-4134.

55. E.C. Theil, P. Turano, V. Ghini, M. Allegrozzi, C. Bernacchioni. J. Biol. Inorg. Chem. 19 (2014) 615-622.

56. T. Tosha, H.L. Ng, O. Bhattasali, T. Alber, E.C. Theil. J. Am. Chem. Soc. 132 (2010) 14562-14569.

57. D.J.E. Huard, K.M. Kane, F.A. Tezcan. Nat. Chem. Biol. 9 (2013) 169-176.

58. K. Uto, K. Yamamoto, N. Kishimoto, M. Muraoka, T. Aoyagi, I. Yamashita. J. Nanopart. Res. 15 (2013) 1516.

59. T.S. Tsapikouni, Y.F. Missirlis. Mater. Sci. Eng. B-Adv. 152 (2008) 2-7.

60. F. Liu, B.J. Du, Z. Chai, G.H. Zhao, F.Z. Ren, X.J. Leng. Eur. Food Res. Technol. 235 (2012) 893-899.

61. K.M. Shin, J.W. Lee, G.G. Wallace, S.J. Lim. Sensor. Actuat. B-Chem. 133 (2008) 393-397.

62. H. Tsukube, Y. Noda, S. Shinoda. Chem.-Eur. J. 16 (2010) 4273-4278.

63. B. Hennequin, L. Turyanska, T. Ben, A.M. Beltran, S.I. Molina, M. Li, S. Mann,

A. Patane, N.R. Thomas. Adv. Mater. 20 (2008) 3592-3596.

64. S. Mann. Nat. Mater. 8 (2009) 781-792.

65. R. Tsukamoto, K. Iwahori, M. Muraoka, I. Yamashita. Abstr. Pap. Am. Chem. Soc. 229 (2005) U938-U939.

66. R.K. Behera, E.C. Theil. Proc. Natl. Acad. Sci. U. S. A. 111 (2014) 7925-7930.

67. K.K.W. Wong, S. Mann. Adv. Mater. 8 (1996) 928-932.

68. F.C. Meldrum, V.J. Wade, D.L. Nimmo, B.R. Heywood, S. Mann. Nature 349 (1991) 684-687.

69. S. Pead, E. Durrant, B. Webb, C. Larsen, D. Heaton, J. Johnson, G.D. Watt. J. Inorg. Biochem. 59 (1995) 15-27.

70. M. Okuda, K. Iwahori, I. Yamashita, H. Yoshimura. Biotechnol. Bioeng. 84 (2003) 187-194.

71. T. Ueno, M. Suzuki, T. Goto, T. Matsumoto, K. Nagayama, Y. Watanabe. Angew. Chem. Int. Edit. 43 (2004) 2527-2530.

72. G.D. Liu, H. Wu, A. Dohnalkova, Y.H. Lin. Anal. Chem. 79 (2007) 5614-5619.

73. G.D. Liu, H. Wu, J. Wang, Y.H. Lin. Small 2 (2006) 1139-1143.

74. F.C. Meldrum, B.R. Heywood, S. Mann. Science 257 (1992) 522-523.

75. K.K.W. Wong, T. Douglas, S. Gider, D.D. Awschalom, S. Mann. Chem. Mat. 10 (1998) 279-285.

76. S.H. Sun, C.B. Murray, D. Weller, L. Folks, A. Moser. Science 287 (2000) 1989-1992.

77. B. Fernandez, N. Galvez, P. Sanchez, R. Cuesta, R. Bermejo, J.M. DominguezVera. J. Biol. Inorg. Chem. 13 (2008) 349-355.

78. S. Abe, K. Hirata, T. Ueno, K. Morino, N. Shimizu, M. Yamamoto, M. Takata, E. Yashima, Y. Watanabe. J. Am. Chem. Soc. 131 (2009) 6958-6960. 
79. I. Blazkova, H.V. Nguyen, S. Dostalova, P. Kopel, M. Stanisavljevic, M. Vaculovicova, M. Stiborova, T. Eckschlager, R. Kizek, V. Adam. Int. J. Mol. Sci. 14 (2013) 13391-13402.

80. D. Dospivova, D. Hynek, P. Kopel, A. Bezdekova, J. Sochor, S. Krizkova, V. Adam, L. Trnkova, J. Hubalek, P. Babula, I. Provaznik, R. Vrba, R. Kizek. Int. J. Electrochem. Sci. 7 (2012) 6378-6395.

81. J. Gumulec, M. Fojtu, M. Raudenska, M. Sztalmachova, A. Skotakova, J. Vlachova, S. Skalickova, L. Nejdl, P. Kopel, L. Knopfova, V. Adam, R. Kizek, M. Stiborova, P. Babula, M. Masarik. Int. J. Mol. Sci. 15 (2014) 22960-22977.

82. R. Konecna, H.V. Nguyen, M. Stanisavljevic, I. Blazkova, S. Krizkova, M. Vaculovicova, M. Stiborova, T. Eckschlager, O. Zitka, V. Adam, R. Kizek. Chromatographia 77 (2014) 1469-1476.

83. A. MaHam, Z.W. Tang, H. Wu, J. Wang, Y.H. Lin. Small 5 (2009) 1706-1721.

84. K. Tmejova, D. Hynek, P. Kopel, S. Dostalova, K. Smerkova, M. Stanisavljevic, H.V. Nguyen, L. Nejdl, M. Vaculovicova, S. Krizkova, R. Kizek, V. Adam. Int. J. Electrochem. Sci. 8 (2013) 12658-12671.

85. R.M. Xing, X.Y. Wang, C.L. Zhang, Y.M. Zhang, Q. Wang, Z. Yang, Z.J. Guo. J. Inorg. Biochem. 103 (2009) 1039-1044.

86. S. Aime, L. Frullano, S.G. Crich. Angew. Chem. Int. Edit. 41 (2002) 1017-1019.

87. S.G. Crich, B. Bussolati, L. Tei, C. Grange, G. Esposito, S. Lanzardo, G. Camussi, S. Aime. Cancer Res. 66 (2006) 9196-9201.

88. Z. Heger, S. Skalickova, O. Zitka, V. Adam, R. Kizek. Nanomedicine 9 (2014) 2233-2245.

89. J.F. Hainfeld. Proc. Natl. Acad. Sci. U. S. A. 89 (1992) 11064-11068.

90. C.J. Sun, H. Yang, Y. Yuan, X. Tian, L.M. Wang, Y. Guo, L. Xu, J.L. Lei, N. Gao, G.J. Anderson, X.J. Liang, C.Y. Chen, Y.L. Zhao, G.J. Nie. J. Am. Chem. Soc. 133 (2011) 8617-8624.

91. K. Park. ACS Nano 7 (2013) 7442-7447.

92. M.E. Davis, Z. Chen, D.M. Shin. Nat. Rev. Drug Discov. 7 (2008) 771-782.

93. H.S. Choi, W.H. Liu, F.B. Liu, K. Nasr, P. Misra, M.G. Bawendi, J.V. Frangioni. Nat. Nanotechnol. 5 (2010) 42-47.

94. R.A. Petros, J.M. DeSimone. Nat. Rev. Drug Discov. 9 (2010) 615-627.

95. A. Makino, H. Harada, T. Okada, H. Kimura, H. Amano, H. Saji, M. Hiraoka, S. Kimura. Nanomed.-Nanotechnol. 7 (2011) 638-646.

96. K.L. Fan, L.Z. Gao, X.Y. Yan. Wiley Interdiscip. Rev. Nanomed. Nanobiotechnol. 5 (2013) 287-298.

97. S. Geninatti Crich, J.C. Cutrin, S. Lanzardo, L. Conti, F.K. Kalman, I. Szabo, N.R. Lago, A. Iolascon, S. Aime. Contrast Media Mol. Imaging 7 (2012) 281-288.

98. J.Y. Li, N. Paragas, R.M. Ned, A.D. Qiu, M. Viltard, T. Leete, I.R. Drexler, X. Chen, S. Sanna-Cherchi, F. Mohammed, D. Williams, C.S. Lin, K.M. Schmidt-Ott, N.C. Andrews, J. Barasch. Dev. Cell 16 (2009) 35-46.

99. F. Danhier, O. Feron, V. Preat. J. Control. Release 148 (2010) 135-146.

100. S.H. Ku, K. Kim, K. Choi, S.H. Kim, I.C. Kwon. Adv. Healthc. Mater. 3 (2014) 1182-1193.

101. E. Falvo, E. Tremante, R. Fraioli, C. Leonetti, C. Zamparelli, A. Boffi, V. Morea, P. Ceci, P. Giacomini, Nanoscale 5 (2013) 12278-12285.

102. H. Okada. J. Pharm. Invest. 44 (2014) 505-516.

103. A. Massaguer, A. Gonzalez-Canto, E. Escribano, S. Barrabes, G. Artigas, V. Moreno, V. Marchan. Dalton Trans. 44 (2015) 202-212. 
104. R. Senthilkumar, D. Sen Karaman, P. Paul, E.M. Bjork, M. Oden, J.E. Eriksson, J.M. Rosenholm. Biomater. Sci. 3 (2015) 103-111.

105. J. Zhao, M.L. Liu, Y.Y. Zhang, H.T. Li, Y.H. Lin, S.Z. Yao. Anal. Chim. Acta 759 (2013) 53-60.

106. R. Yerabolu, J. Hakenjos, W. Henne. Abstr. Pap. Am. Chem. Soc. 244 (2012)

107. X. Lin, J. Xie, L. Zhu, S. Lee, G. Niu, Y. Ma, K. Kim, X.Y. Chen. Angew. Chem. Int. Edit. 50 (2011) 1569-1572.

108. P.S. Low, S.A. Kularatne. Curr. Opin. Chem. Biol. 13 (2009) 256-262.

109. J.P. Dassie, X.Y. Liu, G.S. Thomas, R.M. Whitaker, K.W. Thiel, K.R. Stockdale, D.K. Meyerholz, A.P. McCaffrey, J.O. McNamara, P.H. Giangrande. Nat. Biotechnol. 27 (2009) 839-U895.

110. V. Dapic, V. Abdomerovic, R. Marrington, J. Peberdy, A. Rodger, J.O. Trent, P.J. Bates. Nucleic Acids Res. 31 (2003) 2097-2107.

111. X.D. Wang, J. Dong, X.Y. Liu, Y.Z. Liu, S.Y. Ai. Biosens. Bioelectron. 54 (2014) 85-90.

112. M. Uchida, M.L. Flenniken, M. Allen, D.A. Willits, B.E. Crowley, S. Brumfield, A.F. Willis, L. Jackiw, M. Jutila, M.J. Young, T. Douglas. J. Am. Chem. Soc. 128 (2006) 16626-16633.

113. Z.P. Zhen, W. Tang, H.M. Chen, X. Lin, T. Todd, G. Wang, T. Cowger, X.Y. Chen, J. Xie. ACS Nano 7 (2013) 4830-4837.

114. M. Bottini, C. Sacchetti, A. Pietroiusti, S. Bellucci, A. Magrini, N. Rosato, N. Bottini. J. Nanosci. Nanotechnol. 14 (2014) 98-114.

115. S. Dostalova, R. Konecne, I. Blazkova, M. Vaculovicova, P. Kopel, S. Krizkova, T. Vaculovic, V. Adam, R. Kizek. Mendel Net 2013, Proceedings of International PhD Students Conference, Mendelova univerzita v Brne, Brno, Czech Republic, 2013, p. 198-198.

116. M.G. Ott, M. Schmidt, K. Schwarzwaelder, S. Stein, U. Siler, U. Koehl, H. Glimm, K. Kuhlcke, A. Schilz, H. Kunkel, S. Naundorf, A. Brinkmann, A. Deichmann, M. Fischer, C. Ball, I. Pilz, C. Dunbar, Y. Du, N.A. Jenkins, N.G. Copeland, U. Luthi, M. Hassan, A.J. Thrasher, D. Hoelzer, C. von Kalle, R. Seger, M. Grez. Nat. Med. 12 (2006) 401-409.

117. V. Glaser. Genet. Eng. News 21 (2001) 15-20.

118. F. Levine. Diabetes-Metab. Rev. 13 (1997) 209-246.

119. L. Alvarez-Erviti, Y.Q. Seow, H.F. Yin, C. Betts, S. Lakhal, M.J.A. Wood. Nat. Biotechnol. 29 (2011) 341-U179.

120. E. Mastrobattista, M. van der Aa, W.E. Hennink, D.J.A. Crommelin. Nat. Rev. Drug Discov. 5 (2006) 115-121.

121. C.N. Landen, A. Chavez-Reyes, C. Bucana, R. Schmandt, M.T. Deavers, G. Lopez-Berestein, A.K. Sood. Cancer Res. 65 (2005) 6910-6918.

122. D.W. Pack, A.S. Hoffman, S. Pun, P.S. Stayton. Nat. Rev. Drug Discov. 4 (2005) 581-593.

123. M. Morille, C. Passirani, A. Vonarbourg, A. Clavreul, J.P. Benoit. Biomaterials 29 (2008) 3477-3496.

124. C.Y.M. Hsu, H. Uludag. J. Drug Target. 20 (2012) 301-328.

125. P.H. Tan, C.L.H. Chan, A.J.T. George. Expert Opin. Biol. Ther. 6 (2006) 619-630.

126. N. Liao, Y. Zhuo, Y.Q. Chai, Y. Xiang, Y.L. Cao, R. Yuan, J. Han. Chem. Commun. 48 (2012) 7610-7612.

127. U. Lungwitz, M. Breunig, T. Blunk, A. Gopferich. Eur. J. Pharm. Biopharm. 60 (2005) 247-266. 
128. Z. Yang, X.Y. Wang, H.J. Diao, J.F. Zhang, H.Y. Li, H.Z. Sun, Z.J. Guo. Chem. Commun. (2007) 3453-3455.

129. C.R. Patra, R. Bhattacharya, D. Mukhopadhyay, P. Mukherjee. Adv. Drug Deliv. Rev. 62 (2010) 346-361.

130. F.X. Gu, R. Karnik, A.Z. Wang, F. Alexis, E. Levy-Nissenbaum, S. Hong, R.S. Langer, O.C. Farokhzad. Nano Today 2 (2007) 14-21.

131. J. Chomoucka, J. Drbohlavova, D. Huska, V. Adam, R. Kizek, J. Hubalek. Pharmacol. Res. 62 (2010) 144-149.

132. J.C. Cutrin, S.G. Crich, D. Burghelea, W. Dastru, S. Aime. Mol. Pharm. 10 (2013) 2079-2085.

133. A.H. Ma-Ham, H. Wu, J. Wang, X.H. Kang, Y.Y. Zhang, Y.H. Lin. J. Mater. Chem. 21 (2011) 8700-8708.

134. M.M. Liang, K.L. Fan, M. Zhou, D.M. Duan, J.Y. Zheng, D.L. Yang, J. Feng, X.Y. Yan. Proc. Natl. Acad. Sci. U. S. A. 111 (2014) 14900-14905.

135. X.Y. Liu, W. Wei, Q. Yuan, X. Zhang, N. Li, Y.G. Du, G.H. Ma, C.H. Yan, D. Ma. Chem. Commun. 48 (2012) 3155-3157.

136. N.C. Mougin, P. van Rijn, H. Park, A.H.E. Muller, A. Boker. Adv. Funct. Mater. 21 (2011) 2470-2476.

137. H.W. Huang, Q. Yu, X.S. Peng, Z.Z. Ye. J. Mater. Chem. 21 (2011) 13172-13179.

138. M. Kanekiyo, C.J. Wei, H.M. Yassine, P.M. McTamney, J.C. Boyington, J.R.R. Whittle, S.S. Rao, W.P. Kong, L.S. Wang, G.J. Nabel. Nature 499 (2013) 102-106.

139. L.M. Zhang, Z.X. Lu, Q.H. Zhao, J. Huang, H. Shen, Z.J. Zhang. Small 7 (2011) 460-464.

140. Z.P. Zhen, W. Tang, C.L. Guo, H.M. Chen, X. Lin, G. Liu, B.W. Fei, X.Y. Chen, B.Q. Xu, J. Xie. ACS Nano 7 (2013) 6988-6996.

141. X. Lin, J. Xie, G. Niu, F. Zhang, H.K. Gao, M. Yang, Q.M. Quan, M.A. Aronova, G.F. Zhang, S. Lee, R. Leaprnan, X.Y. Chen. Nano Lett. 11 (2011) 814-819. 